\title{
Empiria como Critério de Vigência do Direito: entre Alf Ross e Herbert Hart
}

\section{Empirical as Criterion of law Effectiveness: between Alf Ros and Hebert Hart}

\author{
Horácio Wanderlei Rodrigues \\ Universidade Federal de Santa Catarina, Florianópolis - SC, Brasil \\ Luana Renostro Heinen \\ Universidade Federal de Santa Catarina, Florianópolis - SC, Brasil
}

\begin{abstract}
Resumo: O positivismo jurídico pauta o Direito na validade formal. No entanto, a teoria do Direito também se debruça sobre outros aspectos mais próximos da empiria para compreender o fenômeno jurídico, busca-se tais elementos nas obras de Herbert Hart e Alf Ross. Para Hart, o conteúdo da regra de reconhecimento, usada para se encontrar a validade de uma norma, deve ser aferido empiricamente em cada sistema jurídico, podendo inclusive (mas não necessariamente) incorporar elementos morais. De maneira distinta, a teoria do realista Ross independe do critério de validade e defende que a vigência é verificável pela aplicação efetiva da norma pelas autoridades jurídicas.
\end{abstract}

Palavras-chave: Validade. Vigência. Herbert L. A. Hart. Alf Ross.

\begin{abstract}
Legal positivism positions the law in the formal validity. However, the law theory also focuses on other aspects of empirical to understand the legal phenomenon, we seek such elements in the works of Herbert Hart and Alf Ross. To Hart the rule of recognition's content, that we can use to meet the validity of the right, should be measured empirically in each legal system and may also (but not necessarily) incorporate moral elements. Differently, the realistic Ross theory is independent of the validity criterion and he argues that the effectiveness is verifiable by the effective application of the law by legal authorities.
\end{abstract}

Keywords: Validity. Effectiveness. Vigência. Herbert L. A. Hart. Alf Ross.

Recebido em: 29/08/2015

Revisado em: 26/10/2015

Aprovado em: 09/03/2016 


\section{Notas Prévias}

Neste artigo propõe-se repensar as categorias validade e vigência do Direito a partir de dois autores: Herbert Hart e Alf Ross. A sua maneira, Hart e Ross trabalham com uma perspectiva de Direito mais empírica do que a do positivismo de Hans Kelsen.

Para Kelsen, uma norma válida é aquela que existe dentro de um determinado ordenamento jurídico, observada sua derivação dinâmica, ou seja, a atribuição de competência para sua produção e sua fundamentação, em última instância, na primeira Constituição histórica e na norma fundamental. A validade de uma norma pertence, segundo Kelsen (2003, p. 11), à ordem do dever ser e não à ordem do ser. $\mathrm{O}$ conteúdo da norma não é considerado em sua aferição da validade, enquanto a eficácia é considerada, mas somente como condição de validade, enquanto mínimo de eficácia ${ }^{1}$.

\footnotetext{
${ }^{1}$ Kelsen admite conexões: a norma precisa ter um mínimo de eficácia (o que implica ser observada pelos indivíduos subordinados à ordem jurídica ou ser aplicada pelo órgão jurisdicional) para que não perca sua validade, porém, o primeiro critério a ser observado é sua adequada derivação a partir de outras normas jurídicas. Isso porque, enfatiza Kelsen, a validade não pode ser reduzida à eficácia: “[...] também não se considera como válida uma norma que nunca é observada ou aplicada. E, de fato, uma norma jurídica pode perder a sua validade pelo fato de permanecer por longo tempo inaplicada ou inobservada, quer dizer, através da chamada desuetudo. A desuetudo é como que um costume negativo cuja função essencial consiste em anular a validade de uma norma existente. Se o costume é em geral um fato gerador de Direito, então também o Direito estatuído (legislado) pode ser derrogado através do costume. [...] A eficácia é uma condição da validade, mas não é esta mesma validade. Isto tem de ser bem acentuado, pois não falta ainda hoje quem procure identificar a validade do Direito com a sua eficácia. É-se levado a tal identificação pelo fato de ela parecer simplificar substancialmente a situação teorética. Esta tentativa, porém, está necessariamente condenada ao fracasso. Não só porque - como se depreende do que antecede - também uma ordem jurídica ou uma norma relativamente ineficazes, quer dizer, ineficazes até certo ponto, podem ser consideradas como válidas, e uma norma absolutamente eficaz, que nem sequer pode ser violada, não é tida por válida porque nem sequer é considerada norma; mas especialmente porque, se se afirma a vigência, isto é, a específica existência do Direito, como consistente em qualquer realidade natural, não se está em posição de compreender o sentido próprio ou específico com o qual o Direito se dirige à realidade e pelo qual precisamente se contrapõe a essa realidade que - apenas se se não identifica com a vigência do Direito - pode ser conforme ou contrária ao Direito. Assim como é impossível, na determinação da vigência, abstrair da realidade, assim também é impossível identificar a vigência com a realidade." (KELSEN, 2003, p. 237-238)
} 
Hart diverge de Kelsen nesse ponto; a validade incorpora, na perspectiva de Hart, mais elementos empíricos e também pode incorporar elementos morais. $\mathrm{O}$ autor inglês pode ser considerado um representante do positivismo jurídico inclusivo ${ }^{2}$, corrente que distingue o Direito como fato do Direito como convenção social. Ao incorporar elementos morais à validade do Direito, o positivismo jurídico inclusivo afirma que pode haver (ou seja, é possível, mas não necessário) elementos morais que condicionem a validade do Direito, conforme convenção feita em determinada sociedade. Na obra de Hart, tal convenção se traduz na regra de reconhecimento que pode incorporar valores morais. Para averiguar se determinada ordem jurídica adota elementos morais condicionantes da validade do Direito, faz-se necessário avaliar empiricamente qual é sua regra de reconhecimento, ou seja, Hart busca a regra de reconhecimento na prática do Direito e não em um modelo teórico previamente construído.

Alf Ross vai além de Hart em seu realismo ${ }^{3}$. Enfatiza a vigência do Direito - procurando, ainda, encontrá-la empiricamente na eficácia do Direito - em detrimento da validade, como faz o positivismo. O realismo, do qual Ross herda sua posição, desenvolveu-se principalmente nos países anglo-saxões que adotam o sistema de common law. Não por acaso, o realismo enfatiza o papel dos juízes na constatação do que é o Direito: norma jurídica é aquilo que aplicam os juízes.

Autores que adotam uma perspectiva empírica do Direito podem contribuir em direcionar o holofote da teoria além do aspecto validade da norma e buscar visualizar outros aspectos importantes do Direito, como sua vigência e eficácia. Assim, busca-se, neste trabalho, discutir a proposta de compreensão do Direito, apresentada por dois autores que atribuem papel central à empiria como o critério de vigência do Direito, Herbert L. A. Hart e Alf Ross.

\footnotetext{
${ }^{2}$ Utilizou-se a classificação apresentada por Dimitri Dimoulis (2006, p. 136-139).

${ }^{3}$ Eric Millard (2000, p. 9) entende que o termo "realismo" utilizado para caracterizar a corrente da qual faria parte Alf Ross pode causar confusões na medida em que pode remeter ao realismo na filosofia platônica, sugere, então, empirismo como um termo mais adequado.
} 


\section{Herbert Hart}

Herbert Hart foi um jurista inglês, herdeiro de Wittgenstein e crítico de John Austin. Uma de suas principais obras, O conceito de Direito, é uma revisão da proposta de Austin, em que Hart propõe um modelo aprimorado sobre o Direito, como contraponto ao modelo simples de Austin (SGARBI, 2009, p. 103).

O interesse do autor inglês é a análise do Direito como instituição linguística e, portanto, social. Considera o Direito como um fenômeno cultural moldado pela linguagem e que a compreensão dessa e de seu emprego contribui para o entendimento do Direito como instituição social. Explicar, no entanto, o caráter normativo do Direito é explicitar como ele pode ser fonte de Direito e obrigações, bem como a maneira pela qual impõe certos requisitos à ação humana.

Vê o Direito como constituindo uma realidade normativa complexa, composta de regras primárias e de regras secundárias. Estima que o intento de defini-lo sobre a base de estabelecer o gênero e a diferença específica não conduz a nenhum resultado útil ou esclarecedor. Esse modo tradicional de definição não é apropriado para a tarefa de uma investigação filosófica sobre a natureza de noções muito gerais e abstratas. A definição de tais noções só pode ser levada a termo em signos tão problemáticos quanto os que busca definir. Assim, a preocupação de Hart é não com investigar conceitos, mas em estabelecer as condições que governam o uso das palavras. A pergunta que se faz é sobre as condições que governam o uso do termo Direito, norma, etc.

Ao analisar o modelo simples de Austin, Hart observa que algumas normas jurídicas aplicam penas aos seus infratores; outras, porém, lhes permitem celebrar contratos, casar, etc. Há também aquelas que instituem as funções e competências de legislador e juiz. Apenas as primeiras se deixam explicar como ordens coercitivas. As segundas concedem faculdades. As normas que concedem faculdades não podem ser assimiladas a ordens coercitivas, como o modelo austiniano fazia.

A partir dessas observações Hart faz a seguinte distinção: (a) são normas primárias aquelas que fixam o que o homem pode ou não, o que 
deve ou não fazer. Estabelecem obrigações e exigem obediência; e (b) são normas secundárias aquelas que concedem faculdades e indicam de que modo se criam, reconhecem, trocam, revogam, aplicam e executam as normas primárias.

Existem três tipos de normas secundárias: (a) as normas de reconhecimento, que especificam as formalidades que uma norma deve reunir para ser juridicamente válida; (b) as normas de modificação, que estabelecem o modo de revogar ou alterar as normas jurídicas; e (c) as normas de decisão - ou adjudicação - que definem como se aplicam e executam as normas jurídicas.

A existência de regras de modificação e de decisão converte o sistema legal em um sistema autorregulativo. Uma das marcas distintivas do Direito é que ele cria os meios por meio dos quais ele mesmo pode ser modificado, bem como os instrumentos para sua própria aplicação e execução.

Já a regra de reconhecimento converte o Direito em um sistema de regras diferenciado e identificável. Um sistema jurídico consiste em uma regra de reconhecimento e em todas as regras que exigem aos membros do sistema judicial atuar de acordo com elas e aplicá-las. A regra de reconhecimento é em si uma regra social. Sua existência e conteúdo podem ser estabelecidos empiricamente, investigando-se os costumes e as práticas dos agentes oficiais.

O requisito mínimo para que exista um sistema jurídico é que seus aplicadores oficiais aceitem e sigam a regra de reconhecimento e que a população, em sua maioria, acate a lei.

Em Hart, a regra de reconhecimento estabelece os critérios para a identificação das normas jurídicas. Mas ela não está necessariamente expressa em algum lugar. Pode existir apenas de modo implícito. Nesse sentido, ela é uma série de critérios de validez jurídica: diz-se que uma norma jurídica é válida quando ela preenche os requisitos impostos pela norma de reconhecimento. Pode-se dizer que a regra de reconhecimento contém as condições que governam o uso do termo Direito em uma determinada sociedade. 
A norma de reconhecimento é a dimensão política fundamental do jurídico, o lugar onde norma e fato se identificam.

Mas embora ela contenha os critérios supremos de validade isso não implica afirmar que desconheça limites. Pelo contrário: ela é a expressão de todos os limites que a realidade social se autoimpõe. Tal visão de efetividade espelha a práxis, a facticidade política que todo Direito pressupõe: "[...] com a regra de reconhecimento, Hart reivindica a necessidade de buscar um critério de identificação das normas válidas e da unidade do sistema jurídico na prática efetiva do direito, e não sob a forma exclusiva de uma ideia." (WARAT, 1995, p. 108).

Entende que definir os conteúdos de um sistema legal é um processo de duas etapas: (a) estabelecer os conteúdos da regra de conhecimento, por meio de uma investigação empírica das práticas tanto dos tribunais como dos juízes; e (b) descobrir que regras satisfazem os critérios fixados na regra de reconhecimento, dizer quais as normas que os juízes devem aplicar de acordo com ela.

Esse autor marcou a diferença entre as duas etapas afirmando que as normas de Direito são válidas se, de acordo com a norma de reconhecimento, os juízes estão obrigados a aplicá-las. Já essa última existe como uma prática social.

Admite ele, no entanto, que o fato de que todo sistema jurídico tenha uma regra de reconhecimento não significa que seja fácil determinar seu conteúdo. Sustenta que a existência do Direito tem por base sua aceitação como guia de conduta pelo menos por parte dos juízes e geralmente por parte da maioria das pessoas. Isso não implica, no entanto, a aprovação moral do Direito.

Em síntese, o Direito é, em Hart, um sistema de normas primárias e secundárias em unidade. Essa é a pedra fundamental de seu pensamento: “A união de regras primárias e secundárias está no centro de um sistema jurídico [...]"4 (HART, 1977, p.123, tradução nossa).

${ }^{4}$ Original: "La unión de reglas primarias y secundarias esta en el centro de un sistema jurídico $[\ldots] . "$ 
O segundo ponto importante no raciocínio hartiano é a afirmação de que existe um aspecto interno da obrigatoriedade jurídica. O Direito não obriga a alguém por ameaçá-lo com uma sanção, mas sim porque esse alguém vive o dever jurídico como o motivo da sanção no caso de não respeitá-lo. O que, porém, não confunde Direito e moral, pois o aspecto interno da obrigatoriedade jurídica pode contradizer a moral corrente. Essa afirmação não nega que o aspecto externo, a probabilidade da sanção, também pertença ao Direito, mas o faz afirmar que o aspecto externo seria impossível sem o interno.

Segundo Hart, a combinação desses dois aspectos revela uma exigência coletiva, duradoura e perseverante, que a sociedade impõe, se for necessário, mesmo que com violência física. Essa exigência se chama Direito. E adverte que é evidente que o aspecto interno pode faltar em alguns homens, porém se estivesse ausente em todos não haveria sociedade.

\section{Alf Ross}

Alf Ross, por sua vez, é um dos principais nomes do realismo jurídico escandinavo, cujo fundador foi Axel Hägerström, tendo sido, posteriormente, desenvolvido pelos juristas suecos, Anders Lundstedt e Karl Olivecrona.

Pode-se visualizar como características do realismo escandinavo: (a) a rejeição de toda metafísica; (b) a delimitação da abordagem científica sobre um fundamento empírico (somente o que é real é cognoscível) (c) o não cognoscitivismo em matéria axiológica (os valores não possuem existência objetiva); e (d) a análise da função prática da linguagem do Direito (as normas) que não se trata de uma linguagem cognitiva, mas constitutiva ou performativa (MILLARD, 2005, p. 2-3).

\footnotetext{
5 "La théorie doit permettre d'élaborer le discours cognitif sur des bases empiriques : le phénomène juridique dont on peut parler est un mécanisme complexe de faits sociaux reposant notamment sur une croyance ou un sentiment d'obligation ou de validité" (MILLARD, 2005, p. 3) Tradução livre: “A teoria deve permitir elaborar o discurso cognitivo sobre bases empíricas: o fenômeno jurídico do qual se pode falar é um mecanismo complexo de fatos sociais que repousa notadamente sobre uma crença ou um sentimento de obrigação ou de validade."
} 
Ross é um herdeiro dessa tradição, mas tem referências teóricas mais complexas, como o normativismo de Kelsen (do qual foi aluno em Viena) e o empirismo lógico ${ }^{6}$. Ross foi um crítico de seu mestre, Kelsen. Divergia dele em dois pontos principais: quanto ao conceito de Direito e sobre o que deveria ser a Ciência Jurídica. Enquanto para Kelsen Direito é norma jurídica válida, para Ross o Direito o é quando existe, quando seja vigente e válido. A validade adquire, no entanto, um sentido distinto em Kelsen e Ross.

Segundo Eric Millard (2000, p. 10), Ross assimilou a validade à existência por duas razões: uma teórica e a outra linguística. A razão teórica é que só se pode constatar que uma norma existe empiricamente, de maneira científica. Assim dizer que uma norma é válida significa: (a) que se entende por validade a existência, ou seja, a aplicação efetiva da norma (qualidade empiricamente verificável e não inerente à norma); ou (b) que a norma válida seria dotada de uma força obrigatória inerente ao conceito de Direito. A segunda perspectiva seria, para Ross, a perspectiva de Kelsen na Teoria Pura do Direito, na medida em que a validade da ordem jurídica é interpretada não como se referindo a um fato verificável, mas como ligada à suposição de uma norma fundamental (segundo a qual nós devemos nos comportar conforme a Constituição globalmente eficaz); isso exprimiria, segundo Ross, uma prescrição moral (MILLARD, 2000, p. 10).

6 “Alf Ross a étudié à Vienne en 1923-1924 pendant que Kelsen y était professeur de droit public et administratif. Le séjour de Ross à Vienne a été sans aucun doute important pour son développement intellectuel, et plusieurs points de la théorie du droit de Ross sont directement importés du travail de Kelsen. Mais tout aussi important pour ce développement a été son séjour à Uppsala en 1928-1929, où il a étudié la philosophie et découvert les écrits et l'enseignement d'Axel Hägerström, qui l'ont conduit à développer une critique de la tentative de Kelsen de séparer la science du droit des sciences sociales." (OLSEN, 2014, p. 35). Tradução livre: “Alf Ross estudou em Viene em 1923-1924 enquanto Kelsen era professor de direito público e administrativo. A estadia de Ross em Viena foi sem dúvida importante para seu desenvolvimento intelectual, e muitos pontos da teoria do direito de Ross são diretamente importados do trabalho de Kelsen. Mas tão importante para esse desenvolvimento foi sua estadia em Uppsala em 1928-1929, onde ele estudou a filosofia e descobriu os escritos e os cursos de Axel Hägerström que o conduziram a desenvolver uma crítica da tentativa de Kelsen de separar a ciência do direito das ciências sociais". 
A razão linguística relaciona-se a uma questão de tradução. Esclarece Millard (2000, p. 11) que Ross traduziu através da palavra validade dois termos diferentes que correspondem ao sentido de em vigor e válido. Isso acabou por gerar algumas ambiguidades; posteriormente, porém, Ross admitiu que sua concepção empírica do Direito prescinde do conceito de validade ${ }^{7}$. Tendo em vista esta questão de tradução, optou-se por utilizar o termo vigência quando nos referirmos à existência da norma jurídica na perspectiva de Ross.

Quanto ao papel a ser desempenhado pela Ciência Jurídica, a divergência entre Kelsen e Ross relaciona-se com o objeto: a ciência kelseniana deve se limitar a descrever as normas jurídicas válidas, enquanto a Ciência Jurídica de Ross deve se pautar pelo critério empírico e descrever as normas vigentes; vigência verificável pela aplicação efetiva da norma pelas autoridades jurídicas. A predição é, também, uma divergência: Kelsen rejeita o papel preditivo da Ciência do Direito (KELSEN, 2006, p. 109), enquanto Ross lhe atribui deliberadamente essa tarefa.

Ross afirmou-se, assim, como um empirista, para quem o Direito encontra-se nos fatos sociais e psicológicos, que são fatos reais, entre os quais o fato de que os indivíduos acreditam que existem normas jurídicas, deveres e autoridades investidas por tais normas.

Ross rejeita, assim, qualquer referência metafísica para auxiliar a explicar o que é o Direito vigente, referência comum, segundo ele, na Fi-

\footnotetext{
7 "Nous pouvons parler avec sens de quelqu'un comme étant soumis à une obligation indépendamment du fait qu'il se sente ou non soumis à elle. Ceci est possible dans la mesure ou la réalité ou l'existence de l'obligation est déduite de l'existence d'une norme. L'existence d'une norme renvoie à un état de choses social qui n'a rien à voir avec sa validité comprise comme une force obligatoire qui lui serait inhérente. Au-delà, il n'est possible d'affirmer la réalité indépendante d'une obligation qu'en fonction d'un cognitivisme moral que pour ma part je rejette." (ROSS apud MILLARD, 2000, p. 10). Tradução livre: "Nós podemos falar com sentido de qualquer um como estando submetido a uma obrigação independentemente do fato de que ele se sente ou não submetido a ela. Isso é possível na medida em que a realidade ou a existência da obrigação é deduzida da existência de uma norma. A existência de uma norma reenvia a um estado de coisas social que não tem relação com sua validade compreendida como uma força obrigatória que lhe seria inerente. Além disso, só é possível afirmar a realidade independente de uma obrigação em função de um cognitivismo moral que eu rejeito".
} 
losofia do Direito que remete à ideia de validade no Direito a "[...] um puro conceito da razão, de origem divina ou existente a priori (independente da experiência) na natureza racional do ser humano" (ROSS, 2000, p. 41). Implicitamente se referindo à Kelsen, Ross faz questão de afirmar que é ridículo buscar uma validade a priori para o Direito.

Para Ross, as intermináveis discussões filosóficas sobre a natureza da ordem jurídica têm sua origem na crença de que o Direito deriva sua vigência de uma ideia a priori. Nesse tipo de raciocínio, a definição do que é o Direito é indispensável quando se trata de estabelecer se determinado sistema pode aspirar a que se lhe outorgue essa denominação. No entanto, abandonados os pressupostos metafísicos, o problema de definição perde interesse. Crê que o problema que deve preocupar o jurista não é o da definição do Direito, mas sim o que consiste em saber como se pode distinguir, desde o ponto de vista do conteúdo, um sistema jurídico nacional, necessariamente individual, de outros conjuntos individuais de normas.

Ross entende como Direito vigente:

[...] o conjunto abstrato de ideias normativas que serve como um esquema interpretativo para os fenômenos do Direito em ação, o que por sua vez significa que essas normas são efetivamente acatadas e que o são porque são experimentadas e sentidas como socialmente obrigatórias. (ROSS, 2000, p. 41)

Nesse sentido, para o autor escandinavo o conceito de vigência possui dois elementos: (a) se refere a real efetividade das regras cuja aplicação se haja estabelecido; e (b) se refere à forma como as regras são sentidas como motivo das ações efetuadas, como socialmente vinculantes.

Um sistema de normas tem vigência se funciona como esquema de interpretação de um conjunto correspondente de ações sociais. Para que isso ocorra e as normas sejam efetivamente observadas é necessário que os destinatários se sintam vinculados por elas. Dessa forma, segundo ele, o Direito vigente é definível sem nenhuma necessidade de recorrer a considerações e explicações metafísicas. 
A constatação de que determinada regra de conduta é Direito vigente, em um determinado tempo histórico dentro de um determinado espaço geográfico, implica, ainda, a previsão de que essa regra servirá de base a futuras decisões jurídicas.

Não pode, no entanto, tal constatação pretender para si uma certeza absoluta. Ross esclarece que não se deve confundir o trabalho dos juristas, como cientistas do Direito, cujo propósito é expor fatos, com a atividade profissional dos advogados, cujo propósito é buscar sempre uma maneira de influir sobre as decisões dos juízes. As interpretações dos primeiros são enunciados descritivos; as dos últimos prescrições.

Segundo ele, olhando-se do ângulo do conteúdo, os preceitos que formam um sistema jurídico nacional estão divididos em dois grupos: (a) as normas de comportamento, que regulam a conduta dos particulares; e (b) as normas de competência, que criam um poder ou autoridade; essas últimas são normas que estabelecem em que casos outras normas, formuladas com sujeição a determinados procedimentos, serão vistas como regras de conduta. Nesse sentido, as normas de competência são normas de conduta indiretamente formuladas.

Para Ross, mais do que dirigidas aos particulares, as normas jurídicas estão verdadeiramente dirigidas aos órgãos jurisdicionais. O conteúdo real de uma norma, no âmbito do Direito, consiste em uma ordem para os tribunais. Nesse sentido, a norma individual aplicada ao particular é somente uma derivação daquela dirigida ao órgão jurisdicional.

Pode-se resumir essa sua posição dizendo que um sistema jurídico nacional é o conjunto de regras relativas à organização e ao funcionamento do aparato coativo estatal.

Entende também que os preceitos jurídicos são, em última análise, normas que determinam em que condições se pode fazer uso do poder coativo estatal. Ou seja, normas para regular o uso da força. Nesse sentido, os fenômenos jurídicos, como equivalentes das normas, são as resoluções dos tribunais. 
Consequentemente, um sistema jurídico nacional é o conjunto de normas que os respectivos juízes consideram socialmente vinculantes, motivo pelo qual as aplicam.

Ross vê a aplicação do Direito pelos juízes como único fato decisivo para determinar a vigência das normas aplicadas. Segundo suas próprias palavras:

[...] o direito estabelece normas para o comportamento dos tribunais, não dos particulares. Portanto, para falar dos fatos que condicionam a vigência das normas devemos atender exclusivamente à aplicação judicial do direito, e não ao direito em ação entre os indivíduos particulares. ${ }^{8}$ (ROSS, 1977, p. 35, tradução nossa)

O Direito pressupõe não apenas certa regularidade na sua aplicação pelos juízes, como também que esses se sintam vinculados pelas normas jurídicas aplicadas.

Compreende um sistema jurídico nacional como o conjunto de regras de conduta concernentes ao exercício da força física. Entende ser equivocada a visão segundo a qual o Direito é formado por normas que contam, para a sua eficácia, com o auxílio da força. Ela pressupõe a falsa crença de que as normas de conduta e as normas que impõem ao juiz a obrigação de sancionar coativamente a violação das primeiras são dois aspectos de uma mesma norma.

Aponta também para o fato de que com a aceitação da concepção de Direito como conjunto de normas de conduta sancionadas pela força estariam excluídas do campo jurídico partes essenciais, como as normas de competência, que carecem de sanção. Reconhece que o vinculo das normas jurídicas com a força consiste no fato de que aquelas regulam a aplicação dessa e não no fato de se encontrarem reforçadas por ela.

Portanto o Direito, para Ross, pode ser caracterizado em função de dois elementos: (a) como conjunto de regras concernentes ao emprego da

\footnotetext{
${ }^{8}$ Original: “[...] el derecho suministra normas para el comportamiento de los tribunales, no de los particulares. Por lo tanto, para hallar los hechos que condicionan la vigencia de las normas debernos atender exclusivamente a la aplicación judicial del derecho, y no al derecho en acción entre individuos particulares."
} 
força; e (b) como conjunto de normas de competência que instituem um conjunto de autoridades e lhes permitem formular normas de comportamento e utilizar a força de acordo com elas; é o aspecto institucional da ordem jurídica. Para classificar outros fenômenos normativos é necessário estabelecer seus aspectos correspondentes em função desses dois pontos apontados com relação ao Direito.

Na opinião de Ross existem fenômenos normativos de configuração institucional análoga a do Direito, mas que se baseiam em sanções diferentes da força física. Exemplos são o direito das associações (estatutos) e o direito das gentes (Direito internacional).

De outro lado há tradições culturais que são a expressão de sentimentos mais ou menos uniformes acerca da conduta que deve ser observada em determinadas circunstâncias. São exemplos as normas morais e os convencionalismos. Esses não são fenômenos institucionais e a desaprovação ou censura que sancionam as suas violações emanam de cada sujeito e não de uma autoridade comum.

Ross afirma que as teorias realistas concordam em afirmar que a vigência do Direito encontra-se em sua efetividade social: uma norma vigente é aquela cujo conteúdo é ativo na vida jurídica da comunidade. As teorias realistas divergem, porém, quanto à definição do que seria essa atividade ou ser ativo. A partir dessa divergência, Ross distingue duas correntes de realismo: psicologista e comportamentista.

Para o realismo, psicologista uma norma vigente é aceita pela consciência jurídica popular; por ser aceita por essa consciência é que a norma é aplicada pelos tribunais. A consciência determina a decisão. Uma investigação sobre a vigência das normas implica, então, em pesquisas sociopsicológicas. O problema que se coloca é como determinar o que é a consciência popular ou quem a representa. Para Ross (2000, p. 99), essa perspectiva acaba reduzindo a consciência popular à consciência individual e convertendo o Direito em um fenômeno semelhante à moral.

Já o realismo comportamentista busca o Direito vigente nas ações dos tribunais. Uma norma vigente é aquela que se tenha bom fundamento para supor que será aplicada pelos tribunais. Essa perspectiva é problemá- 
tica, segundo Ross, pois não é possível predizer a conduta dos juízes por uma mera observação externa dos hábitos dos magistrados.

Ross explica como as duas correntes se opõem:

[...] enquanto esta última [realismo psicológico] define a vigência do Direito de tal sorte que somos forçados a dizer que o Direito é aplicado porque é vigente a teoria comportamentista define o conceito de tal modo que somos obrigados a dizer o Direito é vigente porque é aplicado. (ROSS, 2000, p. 100)

Ross rejeita as duas vertentes e apresenta sua proposta de realismo como uma síntese entre as duas visões: ele é comportamentista na medida em que busca encontrar previsibilidade a partir do comportamento verbal expresso pelo juiz, mas é psicologista ao entender que há uma ideologia normativa que governa e motiva o juiz.

\section{Entre Ross e Hart}

Identifica-se, em concordância com Warat, convergências importantes entre os pensamentos do positivista soft, Hart, e do realista Ross ${ }^{9}$ :

Apesar das diferenças que podem ser notadas nas propostas de Hart [...] y Ross, encontramos nelas elementos comuns, que pressupõem a adesão a uma mesma visão do conhecimento e um acordo tácito sobre o modo em que devem ser abordados os tradicionais problemas ontológicos e epistemológicos da Filosofia do Direito. (WARAT, 1995, p. 102)

\footnotetext{
9 Também Maria Helena Diniz (1988, p. 79-80) vê afinidades entre os posicionamentos dos dois pensadores aqui estudados. Nota-se isso quando ela se refere a Hart nos seguintes termos: "[...] sua teoria apresenta grandes afinidades com o movimento realista jurídico escandinavo, pelo abandono de critérios meta-empíricos de validade do Direito e pela aceitação da existência da ordem jurídica como fenômeno social, isto é, correspondente a uma quantidade de fatos sociais heterogêneos, identificados pela referência a prática efetiva, ou seja, a maneira como os tribunais identificam o que deve ser considerado Direito e a aceitação geral ou aquiescência a respeito destas identificações".
} 
Alf Ross desloca um dos pontos centrais de análise das teorias do Direito: o da condição de sentido jurídico. As teorias jurídicas clássicas, regra geral, têm centrado suas análises, no que se refere a esse ponto, na questão da validade. Em Ross - e de certa forma também em Hart, pelo menos indiretamente - a análise dos critérios de significação jurídica se transfere para a questão da vigência como condição de sentido.

Para Ross, uma norma será vigente se houver fundamentos suficientes (incluída a ideologia normativa) para se acreditar que será aceita pelos juízes e tribunais como base de suas decisões. Sua teoria realista procede à eliminação da dimensão validade como categoria independente da experiência, identificando-a, enquanto vigência, com a eficácia. Nesse sentido, sob o ponto de vista epistemológico, a Ciência Jurídica é uma ciência social empírica que procura interpretar a validade do Direito em termos de efetividade social - a sua vigência. Nessa visão, a expressão Direito vigente é uma predição de que, sob determinadas condições, determinado conjunto de normas será aceito como base para a decisão de futuras controvérsias jurídicas. O Direito não é apenas uma criação do legislador, pois a autoridade judicial, apesar de sentir-se obrigada pelas normas, tem papel constitutivo. A norma jurídica concreta, em que a decisão se traduz, é sempre criação no sentido de que não é mera derivação lógica das normas.

O jurista escandinavo vê o termo Direito vigente como sendo uma expressão que designa o conjunto de ideias normativas que funcionam como sistema de interpretação dos fenômenos jurídicos concretos quando as normas que os regem são efetivamente observadas e quem as observa sente-se por elas vinculado.

Dentro desse contexto os fenômenos jurídicos, como equivalentes das normas, são, em última instância, as sentenças judiciais. Essas, vistas como fatos sociais, são decisivas para determinar a vigência das normas aplicadas.

Mas a vigência, para Ross, está condicionada por dois elementos: (a) por um lado pela eficácia das normas, que coincide com a sua aplicação pelos tribunais; e (b) por outro está atrelada a um elemento interno consistente em que os juízes tenham a convicção de que estão vinculados às normas que aplicam. 
Nesse sentido, a Ciência do Direito busca por meio de proposições descritivas, elaboradas com base na aplicação do princípio da verificação, embasar predições sobre as condutas dos tribunais. Esse aspecto do pensamento de Ross o caracteriza como um realista. Por outro lado, o que a Ciência Jurídica prediz é que normas vão ser utilizadas pelos juízes como fundamento de suas decisões, aqui Ross caracteriza o Direito vigente como conjunto de normas prescritivas. Assim o que o separa das posições não realistas não é uma possível indiferença frente às normas, mas sim o critério adotado para determinar quais normas integram determinado sistema jurídico.

Ross substitui o critério de validade pelo de vigência e o emprega como condição de sentido jurídico. A partir disso sustenta que uma norma e vigente quando e aplicada pelos tribunais. Para ele a vigência deve ser buscada nas sentenças do Judiciário. Essas são vistas como fatos sociais e como condição de significação das normas. Ou seja, as decisões judiciais não constituem o Direito, mas determinam quais as normas que integram o Direito de um país.

Em síntese, Ross não elimina as normas jurídicas como elemento central da definição do jurídico. No fundo ele também fundamenta o sistema pela norma, além do que as decisões judiciais não deixam de ser normas individuais.

Há, ainda, uma contradição no pensamento de Ross, que precisa ser observada: de um lado ele vê as decisões dos tribunais como os fatos que estabelecem quais são as normas vigentes e de outro as normas jurídicas como o fundamento das decisões judiciais. Nesse círculo vicioso, a vigência das normas deriva de sua aplicação e essa pressupõe a vigência daquelas.

Com relação a Hart, pode-se dizer que ele buscou colocar os ideais jurídicos, inclusive a moral, dentro do próprio fenômeno jurídico; não como fundamentos meta-empíricos de validez do direito positivo, mas como algo que pode ser inserido no Direito por convenção. Essa convenção, por sua vez, é empiricamente verificável dentro do próprio direito positivo, exprimindo, consequentemente, uma realidade social. 
A regra de reconhecimento é o ponto central da argumentação exposta por Hart na sua busca de compreensão do Direito. Ela é uma prática social institucionalizada que estabelece os critérios segundo os quais as demais normas pertencem ou não a um determinado sistema jurídico.

A norma de reconhecimento hartiana se assemelha a uma convenção que introduz no sistema jurídico positivo o dever, aos juízes, de aplicarem as regras primárias. $\mathrm{O}$ dever de aceitar o ordenamento vigente. Dessa forma o imaginário judicial se transforma no fundamento de validez do sistema e de suas normas, fazendo com que o cumprimento dessas seja controlado pelos próprios órgãos do sistema e não pela sociedade.

A regra de reconhecimento, em Hart, é a demonstração da necessidade que esse autor vê de um princípio unificador para a força obrigatória do Direito. E ela, não obstante as peculiaridades apresentadas, integra o ordenamento jurídico. É uma regra intrassistemática cuja função primordial é determinar o que é Direito, pois especifica quais as regras primárias que pertencem ao sistema, tratando ao mesmo tempo de estabelecer a sua unidade e hierarquia.

Politicamente, pode-se dizer que o fundamento da regra de reconhecimento é o de legitimação de uma ordem jurídica consolidada. Apresenta-se ela impregnada de fortes componentes ideológicos na medida em que fornecendo um critério de legalidade para a ordem jurídica opera uma dupla tarefa: (a) de consolidação; e (b) de reprodução da ordem vigente, consistindo em forte obstáculo à sua transformação.

Tanto em Ross como em Hart, os critérios adotados para estabelecer o que é Direito possuem um grande peso político-ideológico, tendo em vista que em ambos a racionalidade jurídica está identificada com os órgãos jurisdicionais do sistema e, portanto, corporificada em um local de poder bem melhor encoberto do que os demais órgãos institucionais.

Em Ross vê-se a busca de definição do Direito vigente diretamente a partir das decisões judiciais; são as práticas dos tribunais e dos juízes que definem quais são as normas vigentes em um determinado tempo e espaço. Já em Hart a busca de definição do Direito válido se dá indiretamente a partir das práticas dos tribunais e dos juízes. Para ele essas prá- 
ticas são a fonte para o estabelecimento dos conteúdos da regra de reconhecimento. E esta é que define qual é o Direito válido. Mas em ambos tem-se o mesmo princípio comum: as práticas e decisões judiciais como fonte básica para a estipulação de qual é o Direito a ser aplicado.

Esse deslocamento é efetuado por ambos em dois momentos: (a) a substituição da validade pela vigência como condição de sentido jurídico. Em Ross isso se dá de forma expressa, enquanto em Hart apenas de forma tácita; e (b) a eleição do Poder Judiciário como principal fonte do Direito. Dessa forma, eles omitem (intencionalmente ou não) a visão do Direito como instrumento de poder; o que há efetivamente em todo esse processo de deslocamento é a transferência do centro de decisão do que é Direito em uma sociedade. Esse passa do Legislativo e, em alguns casos, do Executivo - ambos os órgãos eminentemente políticos - para um órgão apresentado pelo pensamento liberal como neutro e imparcial: o Poder Judiciário.

As teorias de Ross e Hart possuem um grande peso político-ideológico, pois auxiliam e reforçam a estrutura de poder vigente que atribui ao Judiciário papel central na definição do Direito. Um Direito legitimado pelo Judiciário é bem mais difícil de ser contestado, politicamente com os instrumentos dos quais se dispõe, do que um Direito construído pelos poderes (expressamente) políticos do Estado.

\section{Conclusão}

O positivismo ao adotar como ângulo de visão o aspecto normativo do Direito, ou seja, o dever ser, acaba por conferir pouca ênfase ao aspecto factual do Direito. O positivismo enfatiza, assim, a validade.

Não se rejeita, no entanto, a importante contribuição do positivismo. Como ressalta Bobbio (1995, p. 143), ao enfatizar o aspecto normativo, o positivismo destaca a atitude operativa que o jurista assume diante do Direito, pois o jurista busca visualizar quais são as normas válidas, já o questionamento sobre a eficácia da norma quase nunca é formulado pelo jurista diante do ordenamento. Além da validade, todavia, parece que é preciso estudar também o aspecto factual, sua eficácia. 
Neste artigo procurou-se em Herbert Hart e Alf Ross instrumentos teóricos que nos possibilitassem conferir maior ênfase à eficácia do Direito, como uma tentativa de encontrar um referencial na Teoria do Direito que nos permitisse ir além da discussão sobre a validade, enfatizada pelo positivismo jurídico.

Analisou-se a teoria de Herbert Hart, em especial sua ideia de validade a ser aferida a partir da regra de reconhecimento. Entende Hart que o Direito não pode ser visto unicamente como ordem coercitiva. Ele é composto também por normas que concedem faculdades e que não podem ser assimiladas a esse tipo de ordem. Além disso, para esse autor, existe um aspecto interno da obrigatoriedade jurídica sem o qual o aspecto externo não seria possível.

Para Hart, o Direito constitui uma realidade normativa complexa, composta por um sistema de normas primárias e secundárias em unidade. Essas últimas dividem-se em normas de reconhecimento, de modificação e de decisão. Hart vê a regra de reconhecimento - cujo conteúdo pode ser estabelecido empiricamente, investigando os costumes e as práticas dos juízes e dos tribunais - como uma série de critérios de validez jurídica que convertem o Direito em um sistema de regras diferenciado e identificável.

Na visão de Hart um sistema jurídico consiste em uma regra de reconhecimento e em todas as regras - validadas por essa norma de reconhecimento - que exigem aos membros do sistema judicial atuar de acordo com elas e aplicá-las.

Também nos debruçamos sobre a proposta teórica de Alf Ross, em especial no que se refere ao aspecto vigência como empiria. Para Ross as normas jurídicas são enunciados prescritivos e estão divididas em dois grupos: normas de conduta e normas de competência. O Direito vigente, na visão de Ross, é aquele que funciona como esquema de interpretação de um conjunto correspondente de ações sociais e a cujas normas os destinatários se sentem vinculados. Ou seja, ele possui um elemento externo, a eficácia, e um elemento interno, a convicção por parte dos juízes de que estão vinculados às normas que aplicam. 
Entende Ross que a aplicação do Direito pelos juízes e tribunais é o único fato que pode determinar quais são as normas vigentes. As decisões do Judiciário não são o Direito, mas determinam quais as normas que integram o Direito. Consequentemente, um sistema jurídico nacional é o conjunto de normas que o respectivo Poder Judiciário considera socialmente vinculante.

Ross desloca - Hart o faz apenas em parte ou de forma tácita - um dos pontos centrais de análise das teorias jurídicas ao transferir a análise dos critérios de significação jurídica da questão da validade para a questão da vigência como condição de sentido. Uma contradição presente na argumentação de Ross é que ele vê as sentenças judiciais como os fatos que definem quais são as normas vigentes e essas como o fundamento das primeiras. Nesse círculo vicioso a vigência das normas deriva de sua aplicação e esta pressupõe a vigência daquelas. Como consequência dessa argumentação tautológica, tem-se que Ross, em última instância, também fundamenta o sistema jurídico pelas normas, inclusive porque as decisões judiciais não deixam de ser normas, mesmo que individuais.

Hart por meio da regra de reconhecimento - cujo conteúdo, na sua visão, pode ser estabelecido através de uma investigação empírica das práticas do poder jurisdicional e de seus membros - transforma o imaginário judicial no fundamento de validez do sistema jurídico e de suas normas. Dessa forma ela é o princípio unificador da força obrigatória do Direito e também um forte instrumento de legitimação da ordem estabelecida.

Nota-se que tanto em Ross como em Hart a racionalidade jurídica está conformada com o Poder Judiciário - tendo em vista que em ambos as práticas e decisões judiciais são a fonte básica para a estipulação de qual é o Direito vigente - e consequentemente corporificada em um espaço de poder bem menos identificável como tal do que os demais órgãos institucionais cuja função é assumidamente política. Essa forma de análise efetuada pelos dois autores omite ideologicamente a possibilidade de se ver o Direito como instrumento de poder.

As teorias estudadas responderam bem à nossa busca. Ajudando-nos a visualizar que, para compreender o direito é preciso procurar analisar o que dizem os tribunais, o que é direito segundo as decisões dos tribunais. 
Pode-se analisar, a partir de Hart, qual é a regra de reconhecimento do direito, isso deve ser feito por meio de uma análise empírica de quais sãos as condições exigidas pelos tribunais para reconhecer uma norma jurídica ou um direito. Já Ross nos diz que o direito vigente é aquele aplicado pelos tribunais, algo que também deve ser aferido empiricamente.

\section{Referências}

BOBBIO, Norberto. O positivismo jurídico: lições de filosofia do Direito. Tradução: Márcio Pugliesi. São Paulo: Ícone, 1995.

DIMOULIS, Dimitri. Positivismo Jurídico: introdução a uma Teoria do Direito e defesa do pragmatismo jurídico-político. São Paulo: Método, 2006. 301 p. (Coleção Professor Gilmar Mendes)

DINIZ, Maria Helena. Compêndio de introdução à Ciência do Direito. São Paulo: Saraiva, 1988.

HART, H. L. A. El concepto de derecho. Trad. de Genaro R. Carrio. Buenos Aires: Abeledo-Perrot, 1977.

KELSEN, Hans. Teoria Pura do Direito. Tradução: João Baptista Machado. São Paulo: Martins Fontes, 2003.

MILLARD, Eric. Deux lectures critiques d'Alf Ross. In: FACULTE DE DROIT DE STRASBOURG, 2000, Strasbourg. Annales de la faculte de droit de Strasbourg - Theories realistes du droit. Strasbourg: Presses Universitaires de Strasbourg, 2000. p. 9-14.

. Le Réalisme scandinave et la Théorie des contraintes. In: TROPER, Michel; CHAMPEILS-DESPLATS, Véronique; GRZEGORCZYK, Christophe (Org.). Théorie des contraintes juridiques. France: Lgdj, 2005. p. 143-154.

OLSEN, Henrik Palmer. Ross ou la validité comme pratique sociale efficace Eric Millard (trad.). Revus: revue de théorie constitutionnelle et philosophie du droit, on- line, v. 24, p. 35-43, 16 dez. 2014.

Disponível em: $<$ http://revus.revues.org/3086>. Acesso em: 18 jul. 2015. 
RODRIGUES, Horácio Wanderlei. Apontamentos críticos às teorias jusfilosóficas de Ross e Hart. Álter Ágora, Florianópolis, v. I, n. 1, p. 55-63, 1994.

ROSS, Alf. Sobre el derecho y la justicia. Trad. de Genaro R. Carrio. Buenos Aires: EUDEBA, 1977.

. Direito e justiça. Tradução de Edson Bini. Bauru: Edipro, 2000. SGARBI, Adrian. Clássicos de Teoria do Direito. 2. ed. Rio de Janeiro: Lumen Juris, 2009.

SQUELLA, Agustin; VERNENGO, Roberto J. (Coord.). Alf Ross: estudios en su homenaje. Valparaiso: EDEVAL, 1984. Revista de Ciencias Sociales, 2 v. Universidad de Valparaiso. n. 25/1 e 25/II, 2. sem. 1984.

WARAT, Luis Alberto. Introdução Geral ao Direito II. Epistemologia jurídica e modernidade. Porto Alegre: Sérgio Fabris, 1995.

Horácio Wanderlei Rodrigues é Doutor e Mestre em Direito pela Universidade Federal de Santa Catarina (UFSC), com estágio de Pós-doutorado em Filosofia na Universidade do Vale do Rio dos Sinos (UNISINOS) e em Educação na Universidade Federal do Rio Grande do Sul (UFRGS). Professor Permanente do Programa de Pós-Graduação em Direito da Faculdade Meridional (PPGD/ IMED). Professor Titular do Departamento de Direito da UFSC. Sócio-fundador do Conselho Nacional de Pesquisa e Pós-Graduação em Direito (CONPEDI) e da Associação Brasileira de Ensino do Direito (ABEDi). Membro do Instituto Iberomericano de Derecho Procesal (IIDP). Coordenador do Núcleo de Estudos Conhecer Direito (NECODI). Pesquisador do Conselho Nacional de Desenvolvimento Científico e Tecnológico (CNPq).

E-mail: horaciowr@outlook.com

Endereço Profissional: Universidade Federal de Santa Catarina - Centro de Ciências Jurídicas - Campus Universitário - Trindade. Florianópolis, SC - Brasil. CEP: 88040970. 
Luana Renostro Heinen é Doutora e Mestre em Direito pela Universidade Federal de Santa Catarina (UFSC). Professora Substituta de Filosofia do Direito do Curso de Graduação em Direito da UFSC. Pesquisadora do Núcleo de Estudos Conhecer Direito (NECODI).

E-mail: luanarheinen@gmail.com

Endereço Profissional: Universidade Federal de Santa Catarina - Centro de Ciências Jurídicas - Campus Universitário - Trindade. Florianópolis, SC - Brasil. CEP: 88040970. 
